\title{
A Model of the Cell Cycle and Cell Division Phasing in a Marine Diatom
}

\author{
By M. R. HEATH*† AND C. P. SPENCER \\ UCNW Marine Science Laboratory, Menai Bridge, Anglesey, Gwynedd LL59 5EH, UK
}

(Received 8 August 1984; revised 3 November 1984)

\begin{abstract}
A model of the cell generation cycle of Thalassiosira pseudonana Hasle and Heimdal (Clone $3 \mathrm{H}$ ) has been produced in which the cell cycle is visualized as being composed of two successive timed periods. The first period is temperature compensated but inversely proportional in duration to the rate of supply of energy (light intensity) whilst the second, culminating in division, has a high $Q_{10}$ but proceeds independently of illumination. Numerical simulations based upon this model and incorporating a feature to encompass variability in individual cell generation times have successfully generated many of the population growth features exhibited by cultures of this species grown under a variety of experimental conditions.
\end{abstract}

\section{INTRODUCTION}

Investigators using a wide variety of algal species have demonstrated that steady state population exponential growth rates vary in a defined manner as a function of light intensity under continuous illumination. Several authors have endeavoured to establish mathematical functions to describe this relationship and these range from the simple use of saturation constants (Middlebrooks \& Porcella, 1971) to the complex expressions derived by Bannister (1979). However, these models, which assume that the population is homogeneous in terms of the individual cells' response to controlling factors, are unable to account for the apparent lack of general relationship between growth rate and total daily illumination encountered in cultures grown under intermittent illumination regimes (Tamiya et al., 1955; Holt \& Smayda, 1974).

Under cyclical illumination conditions most if not all phytoplankton organisms exhibit a degree of cell division phasing which may vary from complete synchrony to only a partial alignment of individual cell generation cycles, depending upon the species and the conditions imposed. Two basic hypotheses have been advanced to describe the mechanism of alignment. (a) Alignment results from the entrainment by alternating light/dark periods of a pre-existing endogenous circadian oscillation or biological clock that regulates the cell cycle. (b) Phasing results from the cell cycle being directly driven by the light/dark periods, representing forced oscillations of the cell cycle.

The concept of circadian clock control of cell division in algae has been described in great detail by several workers (Edmunds, 1976; Ehret, 1974; Pittendrigh, 1975, 1979). However, recent investigations have suggested that many aspects of the cell cycle regulation in certain socalled 'clock controlled' species (e.g. Chlamydomonas) are more adequately explained in terms of sequential timed periods operating independently within the cycle. The phenomenon of cell division phasing in this model clearly represents a forced oscillation of the cell cycle (Bernstein, 1964; Howell \& Naliboff, 1973; Spudich \& Sager, 1980; Donnan \& John, 1983).

The circadian clock model of cell division control does, however, appear to be the only viable explanation of the observed growth patterns of some species, notably dinoflagellates (Hastings \& Sweeney, 1964). The most important evidence for the existence of an endogenous clock lies in the long term persistence of $24 \mathrm{~h}$ periodicity in division rates upon transfer of a phased

† Present address: DAFS Marine Laboratory, PO Box 101, Victoria Road, Torry, Aberdeen AB9 8DB, UK.

Abbreviations: LDP, light-dependent period; LIP, light-independent period. 
population to continuous illumination, even when the mean generation time is well in excess of $24 \mathrm{~h}$. This has led to the concept of 'division gates' in which division in a clock controlled species is said to be restricted to a narrow gate during each $24 \mathrm{~h}$ period which generally occurs during darkness under intermittent illumination regimes (Edmunds, 1978).

The diatoms are conspicuous among the microalgal taxa that have been examined for the great diversity of division phasing patterns, both within and between species, which do not appear to be attributable to any form of clock control (Chisholm et al., 1980; Nelson \& Brand, 1979). In these species, division activity is not restricted to either the light or dark period and although phasing does occur under cyclical illumination, the phase relationships are not readily predictable on the basis of existing models. Many of the faster-growing species undergo several bursts of cell division during each $24 \mathrm{~h}$ period which are repeated in successive periods, but investigators have been unable, by manipulation of the experimental conditions, to induce the synchrony that would be expected of a clock controlled species, that is to produce only a single population doubling per $24 \mathrm{~h}$ period (Chisholm \& Costello, 1980). It has therefore been suggested that diatoms possess a $24 \mathrm{~h}$ division gate but with one or more preferential division times during the gate (Chisholm et al., 1980). Thus the population characteristics do not necessarily reflect the experience of the average cell, each individual being unique in its coupling to the illumination regime. The inference is that diatom cells must have the ability to express a wide range of individual generation times, dictated by non-genetic variability. This is consistent with the very rapid decay of phasing in these species upon transfer to continuous illumination which contrasts sharply with the long-term persistence exhibited by dinoflagellates (Chisholm \& Brand, 1981).

Chisholm \& Costello (1980) have suggested that the high variability in diatom generation times may be explained in terms of a closed loop within the cell cycle with a probability distribution governing exit once the energy requirements for division have been fulfilled. They report that a model based on this principle can under certain conditions produce division periodicity patterns similar to those observed in experimental cultures.

In this paper, an alternative model of the cell cycle control in a marine diatom is presented which is closely analogous to the timer model envisaged for Chlamydomonas (Donnan \& John, 1983).

\section{METHODS}

Thalassiosira pseudonana Hasle and Heimdal Clone 3H (Guillard \& Rhyther, 1962) was maintained in an enriched 24.OS natural seawater medium. The diluted seawater was filtered through a $0.45 \mu \mathrm{m}$ APD Millipore filter and sterilized by autoclaving at $0.35 \mathrm{~kg} \mathrm{~cm}^{-2}$ for $30 \mathrm{~min}$. Enrichment was achieved by the subsequent addition of sterile solutions to produce the following final concentrations: nitrogen (nitrate), $24.0 \mu \mathrm{M}$; phosphorus (phosphate), $2 \cdot 2 \mu \mathrm{M}$; silicon (silicate), $5.0 \mu \mathrm{M}$; iron, $1.8 \mu \mathrm{M}$; manganese, $0.4 \mu \mathrm{M}$; EDTA (disodium salt), $2.0 \mu \mathrm{M}$; vitamin $B_{1}, 0.1 \mathrm{mg} \mathrm{l}^{-1}$; vitamin $B_{12}, 0.5 \mathrm{mg} \mathrm{l}^{-1}$; biotin, $0.5 \mathrm{mg} \mathrm{l}^{-1}$. Further details of the preparation of the medium are presented elsewhere (Heath, 1983).

Data were derived from two types of culture. Growth rates in continuous illumination environments were studied using batch cultures grown in 1 litre Roux flasks. Samples for inoculation were taken from exponentially growing cultures and initial cell concentrations were approximately $1 \times 10^{3}$ cells $\mathrm{ml}^{-1}$. The final density was approximately $5 \times 10^{5}$ cells $\mathrm{ml}^{-1}$, this representing nine population doublings. Exponential growth rates were estimated by linear regression of log-transformed cell concentrations determined on at least six occasions over 3-4 doublings in the mid-exponential phase. Cells were allowed 30 generations to adapt to any new set of conditions after which time the exponential rates determined from successive cultures were within $7.5 \%$ of each other.

The batch culture system is not suitable for studying growth under intermittent illumination, particularly at higher growth rates, since the effects of nutrient limitation towards the end of the exponential phase might be expected to interfere with the cell division phasing. Accordingly a 21 semi-continuous system was employed in which the culture was diluted to a cell concentration of approximately $2 \times 10^{4}$ cells ml $^{-1}$ with fresh medium at $24 \mathrm{~h}$ intervals, thus maintaining the cells in nutrient replete condition. Both batch and semi-continuous cultures were aerated at a rate of approximately $0.25 \mathrm{ml} \mathrm{s}^{-1}$ with filtered air delivered from a small diaphragm pump, whilst in the larger volume cultures sedimentation was also prevented by mechanical stirring.

Both types of culture were incubated in a perspex tank of temperature controlled water and illuminated by equal numbers of Atlas $40 \mathrm{~W}$ Northlight and Gro-lux fluorescent tube lights, in an air conditioned room from which daylight was excluded. 
The light intensity was controlled both by varying the number of fluorescent tubes in use and by enclosing the culture vessel in a wire mesh box. Three such boxes were constructed to provide 30,45 and $65 \%$ reduction in intensity without altering the spectral composition of the light. The duration of illumination was controlled by a Venner $24 \mathrm{~h}$ time switch.

Quantum flux density in the wavelength range $400-700 \mathrm{~nm}$ was measured with a cosine response underwater quantum sensor (Lambda Instruments Corporation LI192S).

The estimation of cell concentration in samples taken from cultures was carried out using a Model $Z_{B}$ Coulter Counter filled with a $100 \mu \mathrm{m}$ diameter orifice tube and using a manometer volume setting of $0.5 \mathrm{ml}$. At least four replicate counts were performed on each sample and coincidence corrections calculated as described in the instrument manual (Coulter Electronics Ltd, 1975). Calibrations were performed at regular intervals using $14.02 \mu \mathrm{m}$ diameter latex particles.

The mean growth rate of cultures incubated in the semi-continuous system was monitored over a period of $7 \mathrm{~d}$ by determining the cell concentration at $24 \mathrm{~h}$ intervals, immediately before and immediately after dilution with fresh medium. The time course of the change in cell concentration within a $24 \mathrm{~h}$ period was then investigated by sampling at intervals of $0.5-1.0 \mathrm{~h}$ for the full duration of an illumination cycle. Instantaneous cell division rate estimates, expressed as percentage of the population dividing per hour, were obtained by calculating the rate between successive cell concentration measurements and plotting the value at the mid-point of the time interval. The data set so obtained was smoothed using a three point moving average which eliminated variation with a period length of less than or equal to twice the sampling interval.

\section{RESULTS AND ANALYSIS}

\section{Formulation of the model}

Fig. 1 shows the relationship between population growth rate expressed as doublings per day, and quantum flux density, determined at two temperatures. At each temperature the transform of these data into the format $x / y$ vs $x$ (effectively a plot of the integrated quantum flux during one population doubling period against the rate of supply of quanta - Fig. 2) is represented by a straight line, at least up to the point where growth rate begins to decline with increasing flux density. The equations describing these straight lines can be related to different aspects of the cell generation cycle since they are of the form

$$
G I=m I+c
$$

where $G=$ mean generation time of cells in the population, $I=$ quantum flux density, $m=$ gradient of regression line, $c=$ regression constant. This reduces to

$$
G=m+c / I
$$

Since $G$ has the dimensions of time, then both $m$ and $(c / I)$ must also have time dimensions only. Thus the generation time $(G)$ can be divided into two sequential parts. (a) A period of duration $(m)$ which is temperature dependent but quantum flux density independent up to the point where growth rate begins to decline with increasing flux density. (b) A period of duration $(c / I)$ which is a function of the quantum flux density but relatively independent of temperature.

The intercept value $(c)$, which has the units of quanta per unit area, may be visualized as the quantum requirement of one cell division, whilst $(c / I)$ represents the time required to deliver that amount of energy.

These two periods will be called the light-independent period (LIP) (duration $m$ ) and the lightdependent period (LDP), respectively. Estimates of the durations of the LDP and LIP derived from the equations describing the data obtained at $7.5^{\circ} \mathrm{C}$ and $17.5^{\circ} \mathrm{C}$ are shown in Fig. 3. These suggest a $Q_{10}$ value for the LDP of approximately 1 , whilst that for the LIP is approximately 4 . No immediate explanation can be offered for this remarkably high $Q_{10}$ value for the LIP.

In this model of the cell cycle, newly produced daughter cells pass through two stages of contrasting physiology before dividing. Under steady state conditions the distribution of cells between these two stages in an asynchronous population is constant and a uniform population growth rate is observed. However, if this distribution is disturbed by a change in conditions then it must be the rate of progress through the second stage in the cycle which exerts the most 


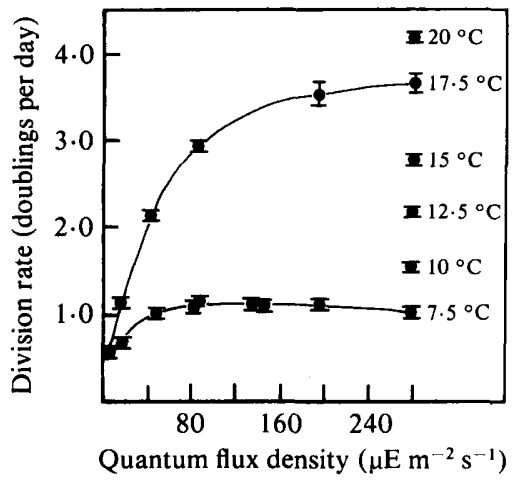

Fig. 1

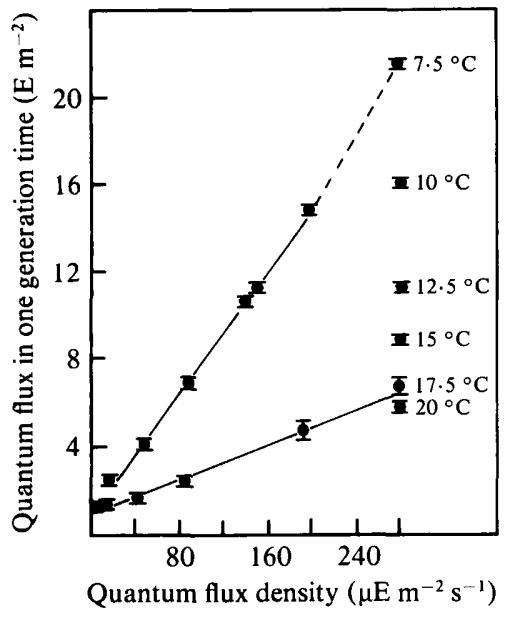

Fig. 2

Fig. 1. Cell division rate of $T$. pseudonana grown under continuous illumination as a function of quantum flux density at various temperatures. Each data point represents the mean of estimates of exponential phase division rates determined from at least five separate cultures. The error bars show the range of values used to calculate the mean.

Fig. 2. Transformation of the data presented in Fig. 1, showing the quantum requirement for cell division as a function of quantum flux density at various temperatures. The error bars show the total range of values arising from the estimates shown in Fig. 1. The regressions of data points corresponding to growth rates determined at $17.5^{\circ} \mathrm{C}$ and $7.5^{\circ} \mathrm{C}$ are both highly significant $\left(17.5^{\circ} \mathrm{C}\right.$ : variance ratio $=$ 34 on 1 and 4 degrees of freedom, $P<0.01 ; 7.5^{\circ} \mathrm{C}$ : variance ratio $=17$ on 1 and 5 degrees of freedom, $P$ $<0.01$ ).

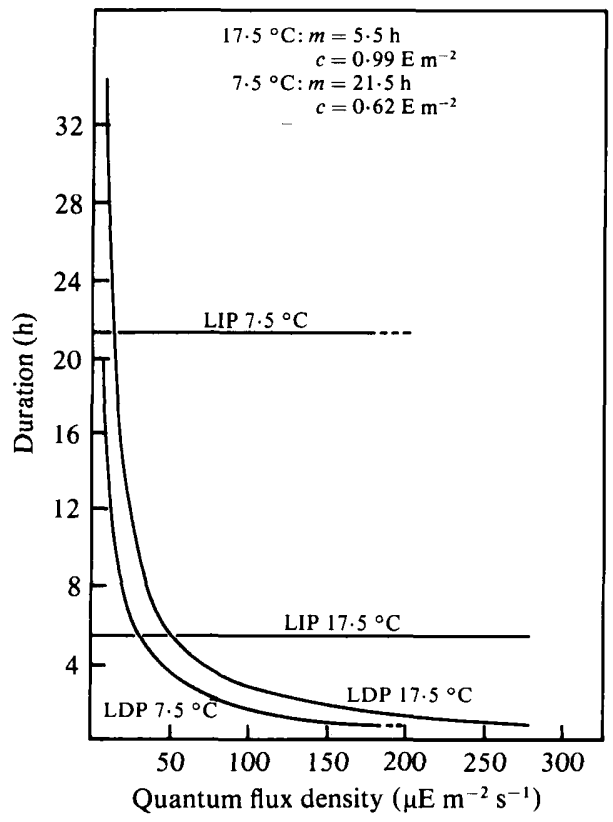

Fig. 3. Estimated durations of the LDP and LIP in the cell cycle using the regression parameters $m$ and $c$ derived from the data shown in Fig. 2. (See text for a description of the parameters $m$ and $c$.) 


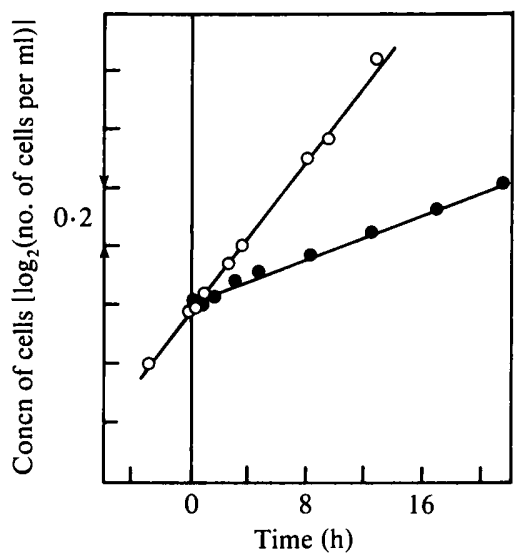

Fig. 4. Changes in cell concentration with time during growth under continuous illumination of $130 \mu \mathrm{E} \mathrm{m}^{-2} \mathrm{~s}^{-1}$ following transfer from $17.5^{\circ} \mathrm{C}$ to $7.5^{\circ} \mathrm{C}$. $\mathrm{O}$, Control culture maintained at $17.5^{\circ} \mathrm{C} ; \mathrm{O}$, subculture transferred to $7.5^{\circ} \mathrm{C}$ at time zero.

immediate control over the population growth rate. This deduction provides a means of determining the sequential order of the two periods in the cycle through the effects of changes in light intensity and temperature on the instantaneous population growth rate. Changes in the factor determining the duration of the period immediately preceding division will have an immediate effect upon the population growth rate whilst the influence of the factor controlling the first period in the cycle will be delayed by an interval equivalent in duration to that of the second period. Experiments to demonstrate this effect were performed as follows. Four populations of $T$. pseudonana were established at $17.5^{\circ} \mathrm{C}$ and exposed to different light intensities $\left(300,130,40\right.$ and $\left.19 \mu \mathrm{E} \mathrm{m}^{-2} \mathrm{~s}^{-1}\right)$ whilst being maintained in exponential growth condition for approximately 20 generations by regular subculturing into new batch cultures. Changes in light intensity or temperature were then effected by dividing a culture in midexponential phase into two parts and exposing one to new conditions whilst maintaining the other under the old regime as a control. The time course of changes in cell concentration was then monitored in both subcultures. Fig. 4 shows the results of a reduction in temperature upon the growth of a population maintained at $130 \mu \mathrm{E} \mathrm{m}^{-2} \mathrm{~s}^{-1}$ whilst the effects of changes in light intensity upon the growth of populations maintained at $17.5^{\circ} \mathrm{C}$ are shown in Fig. 5 .

The data shown in Figs 4 and 5 indicate that the effects of alterations in light intensity upon the instantaneous population growth rate are delayed whilst changes in temperature have an immediate effect. The LIP, that is the high $Q_{10}$ period, must therefore be that which immediately precedes cell division in the generation cycle. Furthermore, the data in Fig. 5 show that the growth rate following a change in light intensity continues at the existing rate for an interval of $4-5 \mathrm{~h}$ duration at $17.5^{\circ} \mathrm{C}$, which is similar to the duration of the LIP at that temperature $(5 \cdot 5 \mathrm{~h})$.

The duration of the LDP is an inverse function of quantum flux density, so conversely at a given temperature the proportion of the cell generation cycle occupied by the LIP will be a direct function of the flux density. As a consequence of this, at high flux densities cells resident in the LIP will represent a larger proportion of the population than at lower densities. This can be expressed mathematically using the age frequency distribution for an asynchronous exponentially growing population derived by Cook \& James (1964): frequency of occurrence of cells of age $(a)$ in the population is given by

$$
n_{0} \cdot 2^{-a}
$$

where $n_{0}=2 \log _{\mathrm{e}} 2$, and $0 \leqslant a \leqslant 1$. For newly produced daughter cells $a=0$, whilst for cells about to divide $a=1$. 

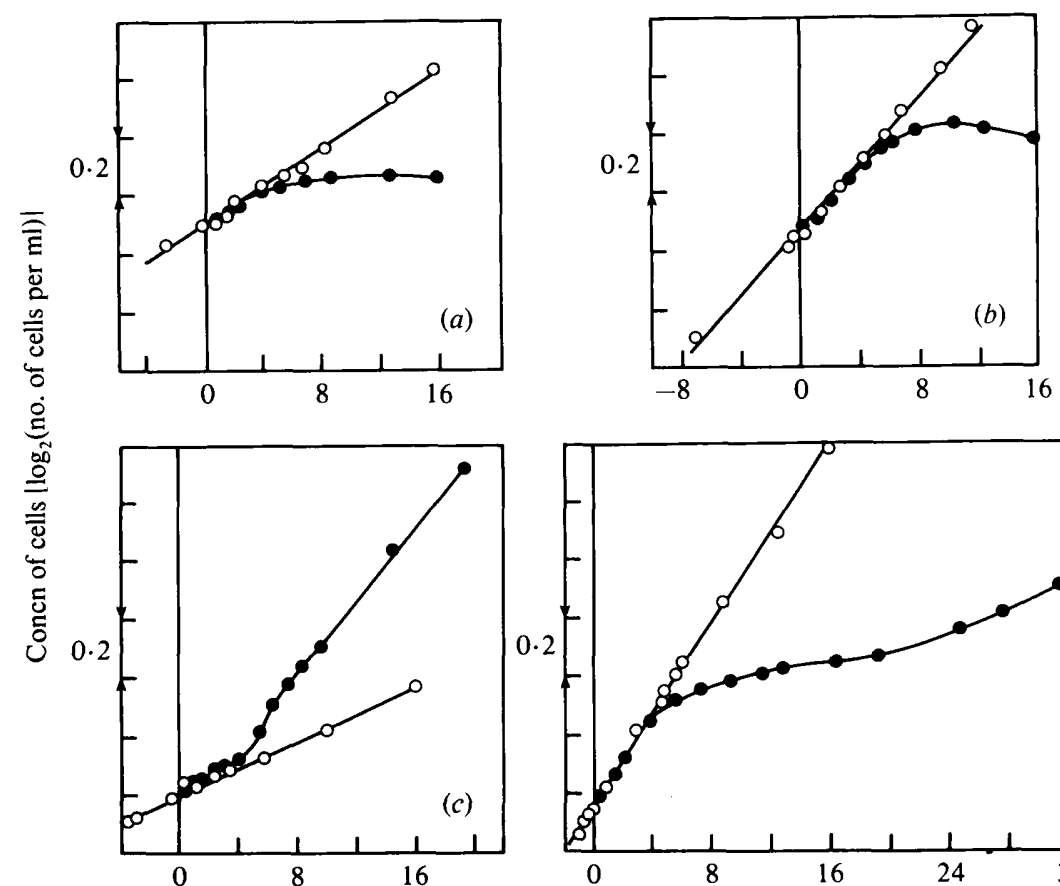

Fig. 5. Changes in cell concentration with time during growth at $17 \cdot 5^{\circ} \mathrm{C}$ following transfer from: $(a)$ continuous illumination of $40 \mu \mathrm{E} \mathrm{m}^{-2} \mathrm{~s}^{-1}$ to darkness; (b) continuous illumination of $130 \mu \mathrm{E} \mathrm{m}^{-2} \mathrm{~s}^{-1}$ to darkness; (c) continuous illumination of $19 \mu \mathrm{E} \mathrm{m}^{-2} \mathrm{~s}^{-1}$ to continuous illumination of $290 \mu \mathrm{E} \mathrm{m}^{-2} \mathrm{~s}^{-1}$; (d) continuous illumination of $300 \mu \mathrm{E} \mathrm{m}^{-2} \mathrm{~s}^{-1}$ to continuous illumination of $19 \mu \mathrm{E} \mathrm{m}^{-2} \mathrm{~s}^{-1} . \bigcirc$, Control culture maintained under original conditions; $\mathbf{O}$, subculture transferred to new conditions at time zero.

Table 1. Practical and theoretical estimates of the fraction of an asynchronous population resident in the LIP as a function of quantum flux density at $17.5^{\circ} \mathrm{C}$

$\begin{array}{cc}\text { Fraction of population } \\ \text { Quantum flux } & \text { able to divide in darkness } \\ \text { density } & \text { or prior to the adoption } \\ \left(\mu \mathrm{E} \mathrm{m}^{-2} \mathrm{~s}^{-1}\right) & \text { of a new growth rate }\end{array}$

$\begin{array}{rll}19 & 0 \cdot 15 & 0 \cdot 21 \\ 40 & 0 \cdot 30 & 0.36 \\ 130 & 0.65 & 0.65 \\ 300 & 0.74 & 0 \cdot 81\end{array}$

\section{Calculated fraction of population in the LIP}

$0 \cdot 21$

0.65

0.81

The fraction of the population older than age $a=x$ is then given by

$$
\begin{aligned}
& n_{0} \int_{\mathrm{x}}^{1} 2^{-a} \cdot \mathrm{d} a \\
= & \left(2^{(1-x)}-1\right)
\end{aligned}
$$

When $x$ corresponds to the age at the end of the LDP this expression represents the fraction of the population resident in the LIP. Under these circumstances $x$ may be expressed in terms of the light intensity $(I)$ and the regression coefficients $m$ and $c$ defined earlier : duration of the LDP $=c / I$, duration of whole cycle $=m+c / I$. Therefore, $x$ at end of LDP $=c /(m I+c)$.

Thus the fraction of the population resident in the LIP is given by

$$
\left(2^{m l /(m l+c)}-1\right)
$$

Fig. 6 shows the way in which the fraction of an asynchronous population resident in the LIP changes with quantum flux density and temperature. The fraction of the population able to divide after the cessation of illumination or continue to divide at the existing rate following a 


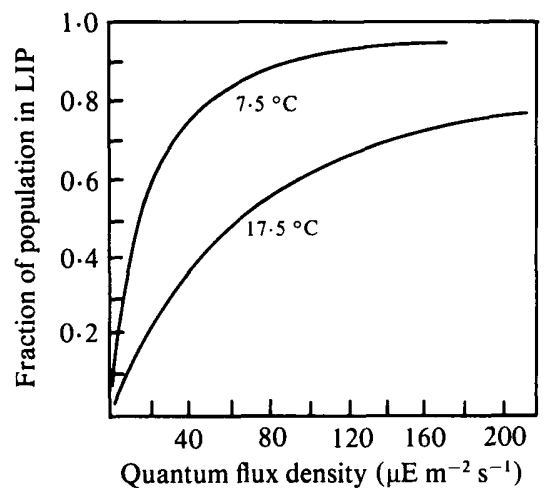

Fig. 6

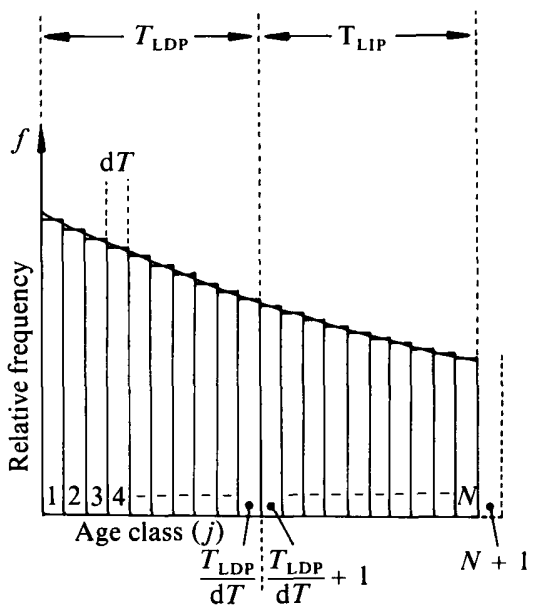

Fig. 7

Fig. 6. Calculated proportions of asynchronous populations growing under steady state conditions which are resident in the LIP of the cell cycle. Proportions have been calculated using the formula derived in the text and the parameters $m$ and $c$ presented in Fig. 3.

Fig. 7. Diagrammatic representation of the basic operation of the digital simulation model of the cell division cycle.

change in quantum flux density provides a useful practical estimator of this. Table 1 indicates reasonable agreement between the two measures.

An important test of this model is its success in accounting for the cell division phasing patterns of this diatom species when grown under intermittent illumination regimes. To this end, a computer simulation model has been developed based upon the simple light dependentlight independent structure of the cell cycle, and also incorporating a function to take into account some natural variability in individual cell generation times. The program listing for this model, written in Algol for use on the UCNW Dec-10 computer, is presented elsewhere (Heath, 1983).

In principle the program functions by dividing the age frequency distribution into discrete blocks or age classes each representing an equal span of time $(\mathrm{d} T)$. The initial frequency of each class, that is the proportion of a steady state asynchronous population resident in each class, is given by the equation derived by Cook $\&$ James (1964) and quoted earlier. The equation is modified by identifying each class by the subscript $(j)$ where $1 \leqslant j \leqslant N+1$ and $N$ is defined as $\left(T_{\mathrm{LDP}}+T_{\mathrm{LIP}}\right) / \mathrm{d} T$. $T_{\mathrm{LDP}}$ and $T_{\mathrm{LIP}}$ are the durations of the LDP and LIP, respectively. The frequency of each age class is then given by

$$
f_{j}=2 \log _{\mathrm{e}} 2.2^{-(j-0.5) / N}
$$

Fig. 7 shows this structure in diagrammatic form.

After a passage of time equal to $\mathrm{d} T$ the individuals within each age class become older by one $\mathrm{d} T$ unit. This occurs throughout the population during periods of illumination but only to cells resident in the LIP during darkness. Cell division is described by doubling the number of individuals in the final class $(j=N+1)$ and reintroducing them into the initial age class $(j=$ 1). The equations describing these operations are as follows.

During illumination: time $=$ time $+\mathrm{d} T$

$$
\begin{aligned}
& f_{j+1}=f_{j} \text { from } j=1 \text { to } j=N \\
& f_{1}=2 \cdot f_{N+1}
\end{aligned}
$$

During darkness: $\quad$ time $=$ time $+\mathrm{d} T$

$$
\begin{aligned}
& f_{j+1}=f_{j} \text { from } j=\left(T_{\mathrm{LDP}} / \mathrm{d} T\right)+1 \text { to } j=N \\
& f_{1}=f_{1}+2 \cdot f_{N+1} \\
& f_{\left(T_{\mathrm{LDP}} / \mathrm{d} T\right)+1}=0
\end{aligned}
$$




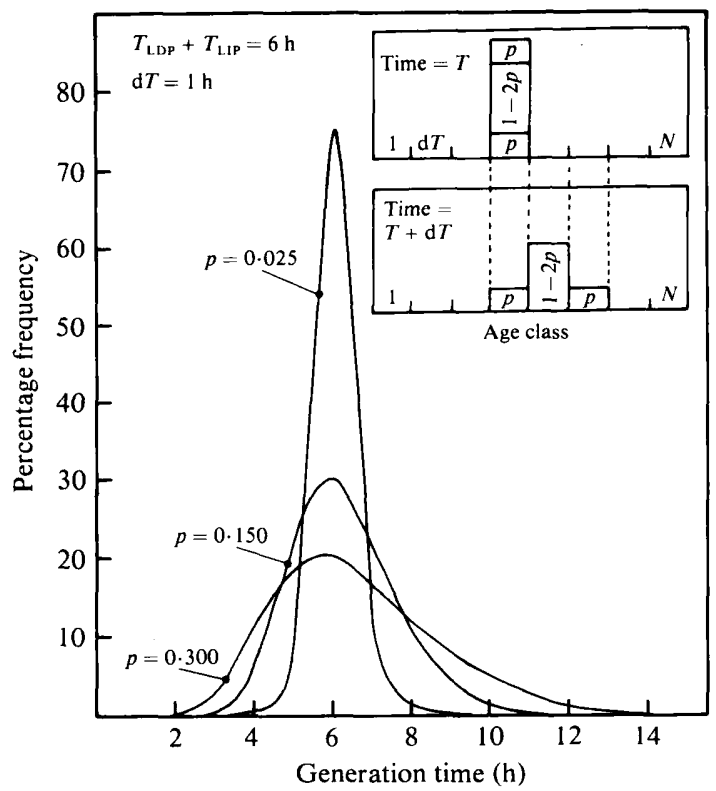

Fig. 8. Diagrammatic representation of the operation of the distribution function $p$ simulating variability in individual cell generation times. The generation time frequency distributions resulting from various values of $p$ were determined by monitoring the proportion of a unit population initially located at age class 1 arriving in class $N+1$ after each time interval $\mathrm{d} T$.

This basic design has been modified to include variability in cell generation times by creating a situation where only a proportion of the cells in each age class develop at a rate equivalent to the mean for the whole population. A fraction $(p)$ develop more quickly, having a shorter generation time, and reach a more advanced stage of development during each interval $\mathrm{d} T$, whilst a further fraction $(p)$ develop more slowly, having a longer generation time than the population mean. This modification is described diagrammatically in Fig. 8. The introduction of $p$ into the model is accomplished by the following modification to the general equation describing the cell generation cycle

$$
f_{j+1}=p \cdot f_{j+1}+(1-2 p) \cdot f_{j}+p \cdot f_{j-1}
$$

This method of introducing variability in individual cell development rates allows all individual generation times between mean $/ 2$ and infinity to exist in the population but the value of $p$ defines the variance of the generation time frequency distribution. The influence of $p$ upon this distribution was investigated by the following method. The model was initiated with the whole population located in the first age class $(j=1)$ and allowed to develop under conditions representing illumination but without simulating cell division, so that the entire population would ultimately accumulate in class $j=N+1$. The relationship between the fraction of the initial population arriving in class $N+1$ after each step and the total time elapsed (cumulative $\mathrm{d} T$ ) is then equivalent to the generation time frequency distribution.

Fig. 8 shows three distributions generated as described, each corresponding to a different value of $p$ but all using the same values of $\mathrm{d} T$ and mean generation time. The distributions show a tendency to skewness in favour of shorter generation times which is encouraging since this feature has been observed in cultured populations of other unicellular micro-organisms (Prescott, 1959; Cook \& Cook, 1962).

It is reasonable to expect that for any species there will be an optimum combination of $d T$ and $p$ to use in the model, giving the best description of that species' particular generation time frequency distribution (assuming this to be reasonably constant). This combination was determined by comparing the data shown in Fig. $5(a, b)$ and other similar sets, with simulations 


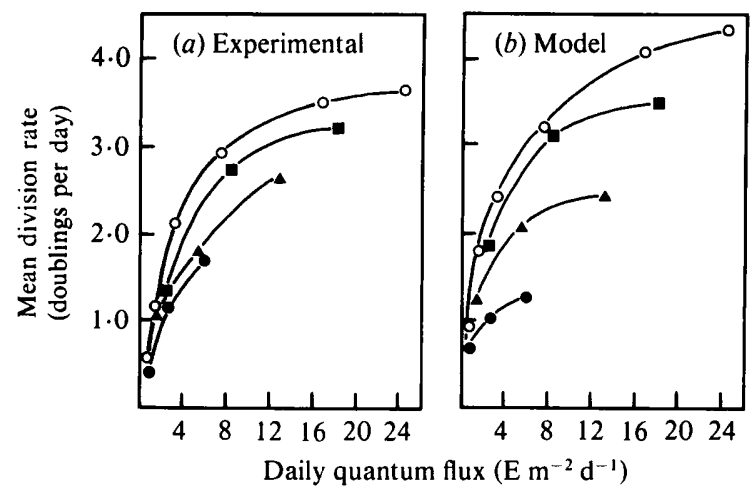

Fig. 9. Relationship between mean division rates (averaged over $24 \mathrm{~h}$ ) and daily quantum flux corresponding to experimental situations $(a)$ and simulations $(b)$ of growth under various illumination regimes at $17 \cdot 5^{\circ} \mathrm{C}$. $\mathrm{O}$, Continuous illumination; $\boldsymbol{\square}, 18 \mathrm{~h}$ light $: 6 \mathrm{~h}$ dark; $\boldsymbol{\Delta}, 12 \mathrm{~h}$ light $: 12 \mathrm{~h}$ dark; $\boldsymbol{O}$, $6 \mathrm{~h}$ light : $18 \mathrm{~h}$ dark.

of growth under the same conditions incorporating combinations of $\mathrm{d} T$ and $p$ ranging from $\mathbf{0 \cdot 2 5}$ to 2.00 and 0.025 to 0.300 , respectively. Comparison was effected by correlation of division rates estimated at equivalent time intervals in the experimental and simulated data. This procedure indicated that values of $1.0 \mathrm{~h}$ for $\mathrm{d} T$ and 0.15 for $p$ were the most appropriate for describing the growth of $T$. pseudonana and these values were used in all further simulations discussed in this paper.

\section{Evaluation of the model}

In order to assess the potential of the model as a valid description of the growth of $T$. pseudonana, the simulated growth under a wide variety of continuous and intermittent illumination regimes was compared to the actual results obtained from laboratory cultures maintained under the same conditions.

Experimental data on growth rates under continuous illumination regimes were obtained from batch culture systems and are presented in Fig. 1, whilst data relating to populations grown under intermittent illumination regimes were derived from semi-continuous cultures. The methods used to estimate the mean growth rates and the time course of changes in instantaneous rates in these cultures are described earlier.

In operating the model to simulate population growth, the durations of illumination and darkness in each intermittent illumination regime defined the number of steps, each of duration $\mathrm{d} T$, to be performed using the appropriate equations describing the cell cycle progression. Continuous illumination was simulated by setting the duration of darkness to zero. The durations of the LDP and LIP used in the model were determined by the light intensity and temperature to be simulated using the relationships derived previously. Simulations of growth under each set of conditions were executed until the output mean population growth rates were identical over successive light/dark cycles. Instantaneous growth rates calculated over each successive $\mathrm{d} T$ interval during a full light/dark cycle were then output for further analysis and comparison with experimentally determined data.

The ability of the model to generate realistic values of mean population growth rate was investigated using cultures grown at $17.5^{\circ} \mathrm{C}$. Mean rates obtained from experimental cultures and simulations of growth under various illumination regimes were plotted against the total daily quantum flux - that is the total quanta delivered during the light period of each $24 \mathrm{~h}$ based illumination regime. These plots (Fig. 9) indicate that the experimental and simulated data are distributed in a very similar fashion with no general relationship between mean population growth rate and daily quantum flux covering all the illumination regimes tested. Taking all these data together there is a significant correlation between the experimentally determined and the simulated population growth rates $\left(r^{2}=0.92, P<0.01\right)$, although the model shows an overall tendency to overestimate the actual rate by a factor of $5-10 \%$. 


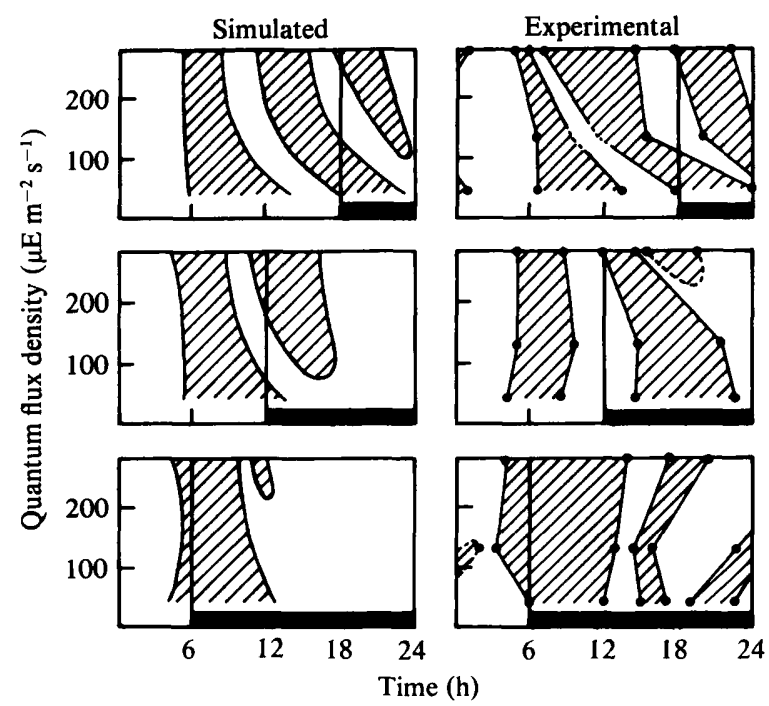

Fig. 10. Effects of quantum flux density on the temporal distribution of overlap periods generated by simulations of growth and experiments carried out at $17.5^{\circ} \mathrm{C}$ under three different $24 \mathrm{~h}$ based light : dark regimes. The shaded areas represent overlap periods, when the instantaneous cell division rate was greater than the mean over the full $24 \mathrm{~h}$ period. Hours of darkness are indicated by bars on the time axis.

The investigations of the time course of changes in the instantaneous growth rate of populations maintained under intermittent illumination regimes indicated a high degree of cell cycle phasing within the populations. In the most extreme cases instantaneous growth rates in experimental cultures varied between -5 and $+38 \%$ dividing per hour within individual $24 \mathrm{~h}$ periods whilst simulations generated rates within the range 0 to $+30 \%$ dividing per hour.

For the purposes of comparing the experimental results and simulations, these data were summarized using the method of Engelberg $(1961,1964)$. In this method, intervals during each light/dark cycle when the instantaneous population growth rate is greater than the mean growth rate over the whole cycle are referred to as overlap periods whose limits are the times during the cycle at which the instantaneous rate is equal to the mean rate. By this technique the time series data sets were characterized in terms of periods of high and low cell division activity, overlap periods representing high or above average activity.

Using the summarized data, the effects of light intensity during the illumination period upon the distribution of cell division activity within each light/dark cycle in simulations of population growth were compared with the effects in experimental cultures. Inspection of the distribution of simulated overlap periods produced under each regime (Fig. 10) indicates that the model can, under appropriate conditions, account for the occurrence of multiple periods of division activity during each illumination cycle. Furthermore, at a given temperature (defined by the duration of the LIP) the time of the onset of the first period following the commencement of illumination is independent of both light intensity and the duration of illumination, and is approximately equivalent to the duration of the $\operatorname{LIP}\left(5.5 \mathrm{~h}\right.$ at $\left.17.5^{\circ} \mathrm{C}\right)$. This independence of the time of onset of the first division period and illumination conditions, and the property of multiple periods of division activity are clearly displayed by the experimental data (Fig. 10).

Simulations of growth, and experiments using cultures growing at $7.5^{\circ} \mathrm{C}$ (Fig. 11) both indicate that reduced temperature (increased duration of the LIP) has the effect of delaying the onset of division activity. Although the model produces a good representation of the timing of division activity within the light/dark cycle at this temperature, there is a serious disparity in the overall increase in cell concentration over the full $24 \mathrm{~h}$ cycle. No immediate explanation of this discrepancy can be offered. 


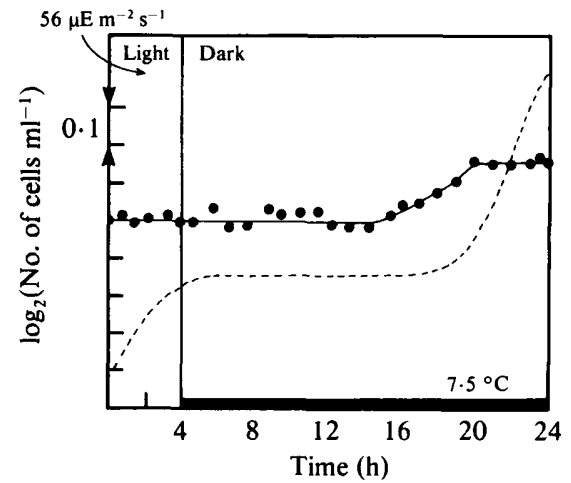

Fig. 11
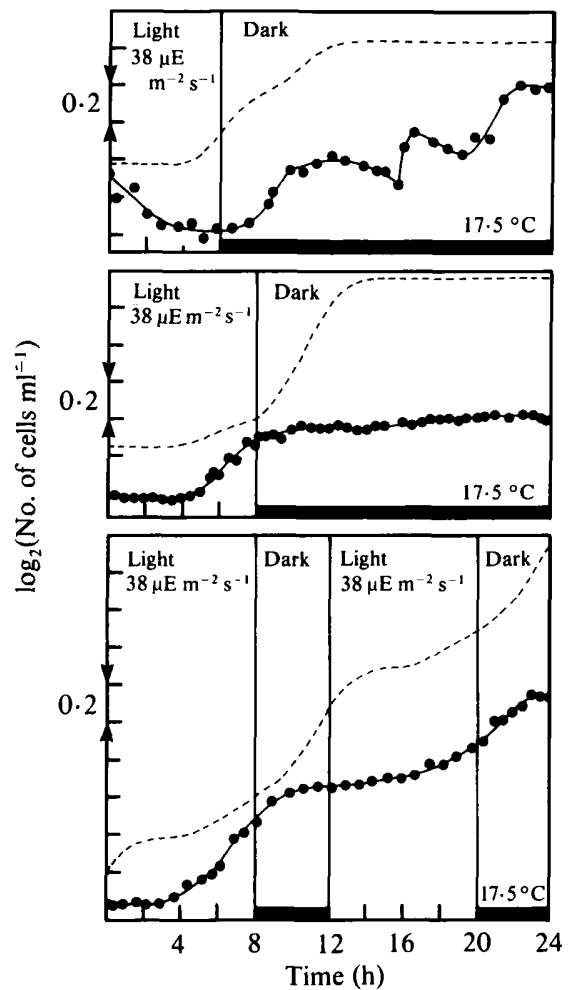

Fig. 12

Fig. 11. Time course of changes in cell concentration experienced in an experimental culture and a simulation of growth at $7.5^{\circ} \mathrm{C}$ under an illumination regime of $4 \mathrm{~h}$ light of $56 \mu \mathrm{E} \mathrm{m}^{-2} \mathrm{~s}^{-1}$ and $20 \mathrm{~h}$ darkness. - Experimental; ----, model.

Fig. 12. Time course of changes in cell concentration in three simulated and experimental cultures maintained at $17.5^{\circ} \mathrm{C}$ and illuminated at $38 \mu \mathrm{E} \mathrm{m}^{-2} \mathrm{~s}^{-1}$, but each experiencing different light : dark cycles. - - , Experimental; ----, model.

The most serious temporal discrepancies between the model and the practical data relating to growth at $17.5{ }^{\circ} \mathrm{C}$ arise from certain regimes employing illumination periods of shorter duration than the mean cell cycle (i.e. LDP + LIP). Under these conditions multiple periods of high cell division rate occur whilst the model can only account for a single period of activity. The additional periods of activity are entirely restricted to the hours of darkness and are characterized by a higher degree of synchrony within each period - that is higher instantaneous division rates - than is generally encountered in the first period of division following the commencement of illumination. It is clear, however, that the occurrence of these periods of activity is very dependent upon the nature of the illumination regime, since although a $6 \mathrm{~h}$ light at $38 \mu \mathrm{E} \mathrm{m}^{-2} \mathrm{~s}^{-1}: 18 \mathrm{~h}$ dark regime produces two such periods, the time series of division rates observed under regimes employing an $8 \mathrm{~h}$ light period of the same quantum flux density are accurately reproduced by the model (Fig. 12).

Cultures in which the additional periods of activity were observed also displayed one or more periods during each $24 \mathrm{~h}$ cycle within which negative growth rates were recorded (Fig. 13). It is most unlikely that these simply represent sedimentation of cells, since the cultures were kept well mixed at all times, and the most reasonable conclusion is that cell death and lysis was occurring during these periods.

Three essential features of the growth of $T$. pseudonana under intermittent illumination regimes have been accounted for by this model.

(1) There appears to be no general relationship between mean population growth rate and the daily energy flux. 


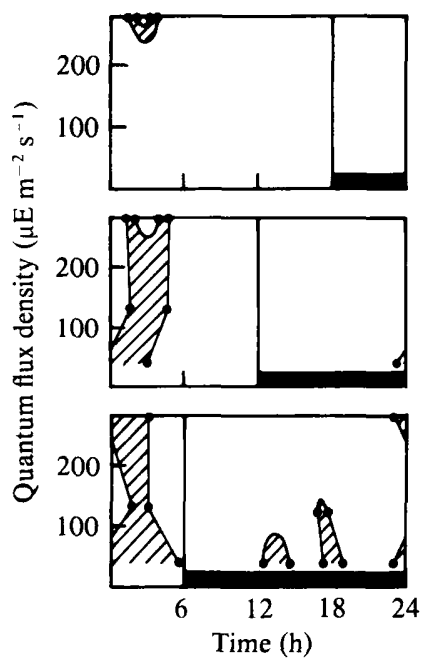

Fig. 13. Effects of quantum flux density on the incidence of periods of negative growth rates (cell lysis) in experimental cultures maintained at $17.5^{\circ} \mathrm{C}$ under three different $24 \mathrm{~h}$ based light:dark cycles. The shaded areas represent periods of negative growth rate. Hours of darkness are indicated by bars on the time axis.

(2) Multiple periods of division activity are a common feature of growth under intermittent illumination regimes.

(3) The time lag between the commencement of illumination under an intermittent illumination regime and the onset of the first period of division activity is independent of illumination intensity or duration but is directly related to temperature.

However, the model is unable to reproduce $(a)$ periods of cell loss observed in populations grown under some intermittent illumination regimes; $(b)$ the division phasing observed in cultures grown under certain conditions of low intensity and short duration illumination periods; $(c)$ the mean growth rate of populations grown at $7.5^{\circ} \mathrm{C}$.

\section{DISCUSSION}

The model described here is clearly not consistent with the possibility of cell division phasing resulting from the entrainment of any endogenous time keeping machinery and is thus in keeping with other reported studies which have failed to identify any such mechanism in diatoms.

The principles of the model are closely analogous to those used to describe the cell cycle of Chlamydomonas (Bernstein, 1964; Howell \& Naliboff, 1973; Spudich \& Sager, 1980; Donnan \& John, 1983). In this species a transition point in the cell cycle has been identified at which individuals acquire a commitment to divide and the cycle progression becomes light independent. Donnan \& John (1983) demonstrated that the pre-commitment period is temperature compensated - a characteristic of a biological timer - whilst the post-commitment period is not.

These two periods in the cell cycle of Chlamydomonas appear to represent phases of markedly different biochemical activity. Donnan \& John (1983) showed that DNA synthesis is restricted to the post-commitment period, whilst Spudich \& Sager (1980) established that starch degradation and respiration rate increase once the commitment to divide has been attained. The latter authors also demonstrated that control of the pre-commitment period is mediated through photosynthetic electron transport between photosystem II and photosystem I.

Tamiya et al. (1953) produced an interpretation of the cell cycle of Chlorella which is also very similar in principle to that described here for $T$. pseudonana. These authors observed that during the generation cycle, cells assume two distinct forms possessing widely different characteristics 
Table 2. Summary of data conforming to the two period model of the cell cycle

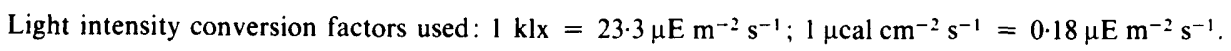

\begin{tabular}{|c|c|c|c|c|}
\hline Species & $\begin{array}{c}\text { Temperature } \\
\left({ }^{\circ} \mathrm{C}\right)\end{array}$ & $\begin{array}{c}\text { Duration of } \\
\text { LIP } \\
(m, \mathrm{~h})\end{array}$ & $\begin{array}{c}\text { Regression } \\
\text { constant } \\
\left(c, \mathrm{E} \mathrm{m}^{-2}\right)\end{array}$ & Reference \\
\hline \multicolumn{5}{|l|}{ Bacillariophyceae } \\
\hline Thalassiosira pseudonana & $17 \cdot 5$ & $5 \cdot 5$ & $0 \cdot 62$ & This paper \\
\hline Thalassiosira pseudonana & $7 \cdot 5$ & $21 \cdot 5$ & 0.99 & This paper \\
\hline Skeletonema costatum & $15 \cdot 0$ & $23 \cdot 0$ & 1.07 & Falkowski \& Owens (1980) \\
\hline Phaeodactylum tricornutum & $15 \cdot 0$ & $11 \cdot 7$ & 0.93 & Quraishi \& Spencer (1971) \\
\hline Asterionella japonica & $18 \cdot 0$ & $11 \cdot 0$ & $4 \cdot 00$ & Kain \& Fogg (1958) \\
\hline Ditylum brightwelli & $20 \cdot 0$ & $10 \cdot 7$ & $2 \cdot 35$ & Paasche (1968) \\
\hline Nitzschia turgidula & $20 \cdot 0$ & $9 \cdot 0$ & 0.96 & Paasche (1968) \\
\hline \multicolumn{5}{|l|}{ Chlorophyceae } \\
\hline Brachiomonas submarina & $15 \cdot 0$ & $15 \cdot 4$ & 1.80 & Quraishi \& Spencer (1971) \\
\hline Chlorella ovalis & $15 \cdot 0$ & $18 \cdot 5$ & $1 \cdot 10$ & Quraishi \& Spencer (1971) \\
\hline Dunaliella primolecta & $15 \cdot 0$ & $15 \cdot 7$ & $2 \cdot 67$ & Quraishi \& Spencer (1971) \\
\hline Dunaliella tertiolecta & $15 \cdot 0$ & $12 \cdot 3$ & $10 \cdot 30$ & Falkowski \& Owens (1980) \\
\hline \multicolumn{5}{|l|}{ Haptophyceae } \\
\hline Pavlova lutheri & $15 \cdot 0$ & $16 \cdot 9$ & 1.02 & Quraishi \& Spencer (1971) \\
\hline Emaliana huxleyii & $20 \cdot 0$ & $11 \cdot 4$ & $1 \cdot 73$ & Paasche (1967) \\
\hline \multicolumn{5}{|l|}{ Dinophyceae } \\
\hline Prorocentrum micans & $20 \cdot 0$ & $19 \cdot 5$ & $11 \cdot 23$ & Kain \& Fogg (1960) \\
\hline
\end{tabular}

which they termed 'light cells' and 'dark cells'. The dark cells - the immediate products of cell multiplication - were smaller, contained more chlorophyll, were more photosynthetically active than the light cells and required light to develop, but the latter were able to develop in darkness and ultimately multiply. By microscopic examination, Tamiya et al. (1953) were able to estimate the proportion of light cells in asynchronous populations grown under various continuous illumination environments. Their results indicate that this proportion varies with light intensity and temperature in an identical manner to the fraction of $T$. pseudonana cells resident in the LIP (Fig. 6). Thus it seems most likely that the dark cell phase is equivalent to the pre-commitment period or LDP, whilst the light cells represent individuals in the post-commitment period or LIP.

The establishment of a model for the cell cycle of a diatom species, the principles of which are already accepted for certain chlorophyte species, and the demonstration that this can account for many features of population growth under intermittent illumination is clearly an important step. However the indications are that this model may be more widely applicable. The basic parameters in the model were originally derived from the relationship between asynchronous population growth rate and light intensity which Quraishi \& Spencer (1971) showed to have a common basis in five species of algae. In a review of these and other relevant data available in the literature all the examples tested conformed to this pattern suggesting that the 'two period' model of the cell cycle may apply to these species also. Table 2 gives details of the data tested and the cell cycle parameters calculated. Furthermore there are clear similarities between this model of the cell cycle in an algal species and models used to describe the yeast and mammalian cell cycles. Beach et al. (1982) have described the cell cycle in yeasts as being composed of an uncommitted pre-replicative phase followed by a committed replicative phase. The committed phase appears to be relatively constant in duration and growth rate is controlled largely by the duration of the uncommitted phase where cells accumulate under poor nutritional conditions. In mammalian cells also, restriction periods in the early part of the cycle $\left(G_{1}\right)$ have been identified as major rate limiting steps. Klevecz (1976) envisaged the mammalian cell cycle as being composed of a loop whose residence time is environmentally determined, followed by a fixed duration period culminating in cell division.

This model has important implications for the analysis of experimental data concerning the characteristics of asynchronous algal populations. It is now clear that interpretations regarding adaptive responses to changes in experimental conditions should be treated with caution since 
the physical environment determines the relative proportions of light-dependent and lightindependent period cells in the population. Thus an increase in light intensity or a decrease in temperature (causing an increase in the proportion of cells in the LIP in the population) might be expected to result in an increase in mean DNA per cell, or a decrease in photosynthesis per cell in the population as a whole. This could occur even in the absence of any response from individual cells, merely as a consequence of the partitioning of biochemical activity within the cell cycle.

This work was carried out during tenure of a Science and Engineering Research Council studentship by M.R.H.

\section{REFERENCES}

BANNISTER, T. T. (1979). Quantitative description of steady state, nutrient saturated algal growth, including adaptation. Limnology and Oceanography 24, 76 96.

Beach, D., Durkacz, B. \& Nurse, P. (1982). Functionally homologous cell cycle control genes in budding and fission yeasts. Nature, London 300, 706 709 .

Bernstein, E. (1964). Physiology of an obligate photoautotroph (Chlamydomonas moewusii). I. Characteristics of synchronously and randomly reproducing cells and an hypothesis to explain their population curves. Journal of Protozoology 11, 56-74.

Chisholm, S. W. \& Brand, L. E. (1981). Persistence of cell division phasing in marine phytoplankton in continuous light after entrainment to light:dark cycles. Journal of Experimental Marine Biology and Ecology 51, 107-118.

Chisholm, S. W. \& Costello, J. C. (1980). Influence of environmental factors and population composition on the timing of cell division in Thalassiosira flutiatilis (Bacillariophyceae) grown on light-dark cycles. Journal of Phycology 16, 375-383.

Chisholm, S. W., Morel, F. M. M. \& Slocum, W. S. (1980). The phasing and distribution of cell division cycles in marine diatoms. In Primary Productivity in the Sea. Brookhaten Symposium in Biology, vol. 31, pp. 281-300. Edited by P. Falkowski. New York: Plenum Press.

CoOK, J. R. \& CooK, B. (1962). Effects of nutrients on the variation of individual generation times. Experimental Cell Research 28, 524-530.

COOK, J. R. \& JAMES, T. W. (1964). Age distribution of cells in logarithmically growing populations. In Synchrony in Cell Division and Growth, pp. 485-495. Edited by E. Zeuthen. New York: Interscience.

COULTER EleCtronics Limited (1975). Instruction Manual for Coulter Counter Model $Z_{B}$ (Industrial), 3rd edn.

Donnan, L. \& John, P. C. L. (1983). Cell cycle control by timer and sizer in Chlamydomonas. Nature, London 304, 630-633.

EDMUNDS, L. N. (1976). Models and mechanisms for endogenous time keeping. In An Introduction to Biological Rhythms, pp. 280-361. Edited by J. D. Palmer. New York: Academic Press.

Edmunds, L. N. (1978). Clocked cell cycle clocks: implications towards chronobiology and aging. Aging and Biological Rhythms. Advances in Experimental Medicine and Biology 108, 125-184.

EHRET, C. F. (1974). The sense of time: evidence for its molecular basis in the eukaryotic gene-action system. Advances in Biological and Medical Physics 15, 47-77.
ENGELBERG, J. (1961). A method of measuring the degree of synchronisation of cell populations. Experimental Cell Research 23, 218-227.

ENGElberG, J. (1964). Measurement of degree of synchrony in cell populations. In Synchrony in Cell Division and Growth, pp. 497-508. Edited by E. Zeuthen. New York: Interscience.

FALKowski, P. G. \& OwENS, T. G. (1980). Light-shade adaptation - two strategies in marine phytoplankton. Plant Physiology 66, 592-595.

Guillard, R. R. L. \& Rhyther, J. H. (1962). Studies of marine phytoplanktonic diatoms. I. Cyclotella nana Hustedt, and Detonula confervacea (Cleve) Gran. Canadian Journal of Microbiology 8, 229-239.

Hastings, J. W. \& SWEeney, B. M. (1964). Phased cell division in marine dinoflagellates. In Synchrony in Cell Division and Growth, pp. 307-321. Edited by E. Zeuthen. New York: Interscience.

HEATH, M. R. (1983). The effects of light and temperature on the growth and plastid pigments of Thalassiosira pseudonana. PhD thesis, University of Wales.

Holt, M. G. \& Smayda, T. J. (1974). The effect of daylength and light intensity on the growth rate of the marine diatom Detonula confervacea. Journal of Phycology 10, 231-237.

Howell, S. H. \& NalibofF, J. A. (1973). Conditional mutants in Chlamydomonas reinhardtii blocked in the vegetative cell cycle. Journal of Cell Biology 57, 760772.

KaIN, J. M. \& FogG, G. E. (1958). Studies on the growth of the marine phytoplankton. I. Asterionella japonica Gran. Journal of the Marine Biological Association of the United Kingdom 37, 394-413.

KaIN, J. M. \& FogG, G. E. (1960). Studies on the growth of marine phytoplankton. III. Prorocentrum micans Ehrenberg. Journal of the Marine Biological Association of the United Kingdom 39, 35-50.

KleveCZ, R. R. (1976). Quantized generation time in mammalian cells as an expression of the cellular clock. Proceedings of the National Academy of Sciences of the United States of America 73, 40124016.

Middlebrooks, E. J. \& Porcella D. B. (1971). Rational multivariate algal growth kinetics. Journal of the Sanitary Engineering Division, Proceedings of the American Society of Ciril Engineers 97(SA1), 135140.

Nelson, D. M. \& Brand, L. E. (1979). Cell division periodicity in 13 species of marine phytoplankton on a light : dark cycle. Journal of Phycology 15, 6775.

PAASCHE, E. (1967). Marine plankton algae grown with light-dark cycles. I. Coccolithus huxleyi. Physiologia Plantarum 20, 946-956. 
PAASCHE, E. (1968). Marine plankton algae grown with light-dark cycles. II. Ditylum brightwelli and Nitzschia turgidula. Physiologia Plantarum 21, 66-77.

PitTEndRigh, C. S. (1975). Circadian clocks: what are they? In The Molecular Basis of Circadian Rhythms. Report of the Dahlem Konferenzen Berlin, Life Sciences Research Report, vol. 1, pp. 11-48. Edited by J. W. Hastings \& J. Schweiger. Berlin: Abakon Verlagsgesellschaft.

PitTEndRigh, C. S. (1979). Some functional aspects of circadian pacemakers. In Biological Rhythms and their Central Mechanism, pp. 3-12. Edited by $\mathrm{M}$. Suda, O. Hayaishi \& H. Nakagawa. Amsterdam: Elsevier/North Holland Biomedical Press.

Prescott, D. M. (1959). Variations in the individual generation times of Tetrahymena geleii HS. Experimental Cell Research 16, 279-284.
Quraishi, F. O. \& SPENCER, C. P. (1971). Studies on the growth of some marine unicellular algae under different artificial light sources. Marine Biology 8 , 60-65.

Spudich, J. L. \& SAGER, R. (1980). Regulation of the Chlamydomonas cell cycle by light and dark. Journal of Cell Biology 85(1), 136-145.

TamiYa, H., Shibata, K., Sasa, T., Iwamura, T. \& Morimura, Y. (1953). Effect of diurnally intermittent illumination on the growth and some cellular characteristics of Chlorella. Carnegie Institute of Washington Publication 600, 76.

TamiYa, H. Sasa, T., NiheI, T. \& Ishibashi, S. (1955). Effects of variation of day-length, day and nighttemperatures, and intensity of daylight upon the growth of Chlorella. Journal of General and Applied Microbiology 4, 298-307. 